\title{
Contrasting characteristics in increasing and decreasing phases of the Nerita japonica (Mollusca: Gastropoda) population on a boulder shore
}

\author{
Yoshitake Takada
}

Received: 7 December 2007 / Accepted: 19 April 2008/Published online: 24 May 2008

(C) The Society of Population Ecology and Springer 2008

\begin{abstract}
The present study demonstrated the seasonal and annual fluctuations in population characteristics of Nerita japonica on a boulder shore at Amakusa, Japan, and examined key characteristics in the increasing and decreasing phases for population monitoring. Monthly quantitative quadrat sampling and subsequent mark-recapture experiments were carried out during two periods: from April 1989 to July 1990 (1st period), and from August 1991 to November 1992 (2nd period). The density of the population was in a decreasing phase during the 1 st period and in an increasing phase during the 2 nd period. The density increase coincided with the extension of the vertical distribution range to a lower tide level, increase in the number of recruitment events, increase in the proportion of juveniles within the population, and increase in the survival of juveniles and adults. The growth rate was slightly increased but the average shell length of adult cohorts did not show any change. Additional observations showed a continued density increase and range extension until 1994. On the other hand, the density decrease coincided with recruitment failure and a low rate of survival with an unchanged range of the vertical distribution. Thus, for monitoring the population of $N$. japonica, recruitment success and changes in density and distribution range are key characteristics, but the shell size is not. These findings show the potential usefulness of $N$. japonica as an indicator of the shore environment.
\end{abstract}

\section{Y. Takada}

Amakusa Marine Biological Laboratory, Kyushu University,

Reihoku, Kumamoto 863-2507, Japan

\section{Present Address:}

Y. Takada $(\bowtie)$

Japan Sea National Fisheries Research Institute,

5939-22 Suido-cho, Niigata 951-8121, Japan

e-mail: yotak@affrc.go.jp
Keywords Annual fluctuation - Direct-developing · Intertidal $\cdot$ Recruitment $\cdot$ Vertical distribution

\section{Introduction}

Understanding patterns and processes underlying population fluctuations is of central interest in the study of population dynamics (Cappuccino 1995). In marine habitats, however, it is generally difficult to delineate local populations of a species because of the strong influence of non-local factors, such as environmental correlations between local habitats with oceanic current and prevalence of external fertilization and planktonic larval stage in the life history of marine organisms (Grimm et al. 2003). Shore communities typically consist of species with a wide range of dispersal modes, from planktonic to direct development (Pechenik 1999; Grantham et al. 2003), and thus conservation management strategies must consider all the species with different dispersal modes. In order to monitor shore communities for environmental conservation, it is desirable to examine as many species as possible. However, due to limitations of budget, time, and/or suitable expertise, it is difficult to monitor all the species in a shore community. The concept of 'indicator species' arises from these constraints (Jones and Kaly 1996). Thus, 'indicator species' should have specific characteristics to detect present status of the shore environment conveniently and reliably.

Nerita japonica Dunker (Mollusca: Gastropoda) is, unlike the majority of the other benthic shore invertebrates, characterized by internal fertilization without a planktonic dispersal stage (Koike 1996). Local distributions of $N$. japonica along shores are patchy (Abe 1980) and these patches (from $10 \mathrm{~m}$ to $1 \mathrm{~km}$ scale; Takada, personal observation) can be regarded as local populations that have 
their own dynamics (Grimm et al. 2003). Because of its characteristic life history, $N$. japonica has attracted the attention of conservation-oriented researchers. In the 1970s and 1980s, some local populations in Tanabe Bay $\left(34^{\circ} \mathrm{N}\right.$, $135^{\circ} \mathrm{E}$ ), central Honshu, Japan, became extinct (Abe 1980; Ohgaki 1989) and subsequently have not recovered (Takenouchi and Yamato 2002). Abe (1980) inferred that the characteristic life history of $N$. japonica, that is the absence of a planktonic dispersal stage and the short life span (3-4 years), made the species sensitive to local environmental stresses that caused the local extinction while other co-occurring shore gastropods were able to maintain their populations. Because populations of $N$. japonica are locally isolated, studies on the dynamics of $N$. japonica will provide basic knowledge for the local shore environment and for comparison with other co-occurring species with a planktonic dispersal stage. However, patterns and processes of population fluctuations in $N$. japonica have not been understood well, except for size structure and growth (Suzuki 1935; Abe 1980; Nakano and Nagoshi 1980, 1983; Takenouchi and Yamato 2002).

The purposes of this study are to examine seasonal and annual fluctuations in a population of $N$. japonica on a boulder shore. Vertical distribution on the shore, size structure, growth rate, and survival rate are compared as key characteristics between the two periods of observation. Annual variations in these population characteristics are demonstrated by long-term observations that have rarely been done on boulder shores (e.g., Takada 2007). Then, the potential applicability of $N$. japonica as an indicator species for environmental monitoring is discussed.

\section{Materials and methods}

\section{Study area}

The study was carried out on a moderately sheltered shore on the eastern side of Magarizaki spit $\left(32^{\circ} 31^{\prime} \mathrm{N}, 130^{\circ} 02^{\prime} \mathrm{E}\right)$ on Amakusa Shimoshima Island, western Kyushu, Japan (Fig. 1a). The shore slopes gently (ca. $3^{\circ}$ ) and the whole intertidal zone is covered by cobbles and small boulders (long axis $<50 \mathrm{~cm}$, hereafter referred to as boulders). These boulders are ovular, and composed of weathered chert and rhyolite. The boulders are stable except during severe spring gales or summer typhoons. The tide is semidiurnal and the mean tidal range is $3.3 \mathrm{~m}$ during the spring tides. Nerita japonica occurred in the high and mid-intertidal zones all along the east side of Magarizaki spit (Takada and Kikuchi 1990, 1991). On the upper surface of the boulders in the high and mid-intertidal zones, macroscopic $(>1 \mathrm{~mm})$ sessile organisms are almost absent. The characteristics of the benthic community on this boulder shore have been described in detail elsewhere (Takada and Kikuchi 1990, 1991).

Study organism

Nerita japonica is dioecious with internal fertilization and oviparous. Females produce and attach egg capsules onto rocks or boulders (Habe 1960; Paruntu and Tokeshi 2003). Without any planktonic dispersal stages, 1-16 juveniles crawl out from an egg capsule (Koike 1996; Paruntu and Tokeshi 2003). Spawning season of N. japonica in Amakusa has been reported to be May to September (Habe 1960) and also from April to September with a peak in mid-summer (Paruntu and Tokeshi 2003). Nakano and Nagoshi (1980) reported that the minimum reproductive size of females was $10 \mathrm{~mm}$ in shell length, considering that $N$. japonica of this size develops a crystal sac which secretes and stores reinforcement minerals for the egg capsules (Sasaki 1998). Individuals of N. japonica forage on microalgae growing on the boulders mainly during nighttime low tides (Takada 2001). Because of the gentle

(a)

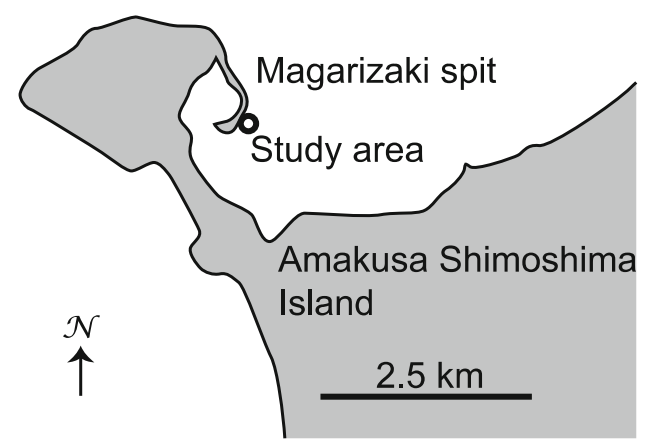

(b) (m)

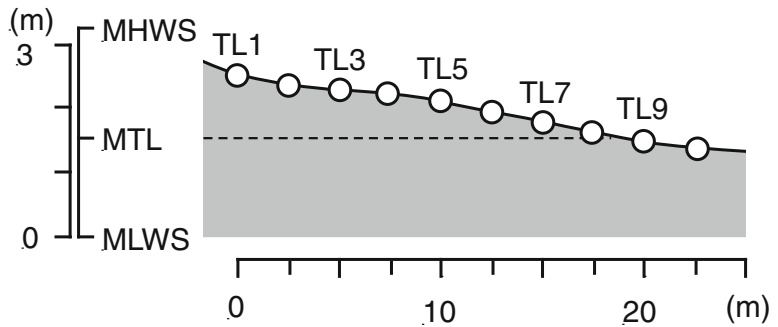

(c)

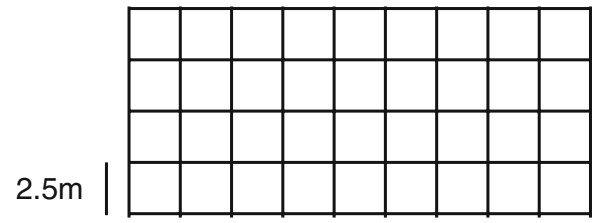

Fig. 1 a Map of the study area and $\mathbf{b}$ profile of the boulder shore at Amakusa, Japan. Ten tide levels (circles) and five transect lines were set on the shore. c Arrangement of research plots. Longer axes indicate transect lines in (b) and shorter axes were set parallel to the shoreline. Quantitative sampling and mark-recapture procedure on Nerita japonica was carried out at the intersection points of the $2.5-\mathrm{m}$ grid 
slope of the shore and the low mobility of the snails, they do not move out of the same zone on the shore during their normal foraging excursions.

\section{Sampling and mark-release method}

Monthly quantitative samplings and subsequent markrelease experiments were carried out during two periods: 1st period from April 1989 to July 1990, and 2nd period from August 1991 to November 1992. On the shore, I set up ten tide levels and five transect lines at $2.5-\mathrm{m}$ intervals (Fig. 1b) on the slope in order to cover the entire vertical distribution range of $N$. japonica. The highest tide level (TL 1) was located $1.0 \mathrm{~m}$ above the MTL (mean tide level) and the lowest (TL 10) at $0.2 \mathrm{~m}$ below the MTL. At each intersection point of the ten tide levels and five transect lines (Fig. 1c), four replicates of a $0.1-\mathrm{m}^{2}$ quadrat were set contiguously and permanently fixed. Thus, the 20 replicate quadrats at each tide level (200 quadrats in total) were sampled during the survey each month.

All the N. japonica in each quadrat found with the naked eye were sampled, and the shell length (maximum shell length at the aperture) was measured to an accuracy of $\pm 0.05 \mathrm{~mm}$ with vernier calipers. These snails were marked with non-toxic paints (Paint-Marker, Mitsubishi, Japan) and coated with glue (Aron-Alpha, Konishi, Japan) at the outer margin of the aperture. Color combinations were changed with the sampling month and tide levels. The snails were released in the same quadrats where they were caught within $24 \mathrm{~h}$ after sampling. During the sampling, each boulder in the quadrats was turned over and then replaced as closely as possible in the same position as before. Considering the mobility of the snails and interval between samples, any disturbance caused by the previous sampling was considered to be negligible. I assumed that, as the sampling area was positioned at the center of the dense patch of $N$. japonica extending at least $40 \mathrm{~m}$ along the shore (Takada and Kikuchi 1991), any loss via horizontal migration from both sides of the sampling area was balanced by migration into the area. Furthermore the mobility of $N$. japonica is limited in comparison to other co-occurring gastropods (Takada 1996, 2003; and unpublished data).

To demonstrate long-term annual changes in the population characteristics, additional sampling was carried out three times in winter: January 1991, November 1993, and December 1994. On these sampling occasions, snails in the permanent quadrats were sampled and measured as mentioned above, but they were released without marking.

\section{Data analysis}

The magnitude of the vertical migration of $N$. japonica was estimated based on the relative tide levels where the marked snails were released and recaptured. The recaptured snails were categorized into three migration patterns: upper migrated snails which were recaptured at a higher tide level than the released tide level, resident snails which were recaptured at the same tide level where they were released, lower migrated snails which were recaptured at a lower tide level than the released tide level. In order to detect monthly fluctuations in the vertical migration, data of the snails recaptured after a 1-month period were used to estimate the percentages of the above three patterns relative to the total number of the recaptured snails. Homogeneity of the monthly migration was tested by a goodness-of-fit test using $G$ statistics after the two periods of data (AprilJuly in 1990 and August-October in 1991) were combined to avoid small expected frequency $(<1)$.

In order to demonstrate temporal fluctuations in the vertical distribution, average tide level of the population was calculated. The average tide level (ATL), which was estimated by the sum of products of a tide level $\left(\mathrm{TL}_{i}\right)$ and the number of individuals at the given tide level $\left(N_{i}\right)$ divided by the total number of individuals (ATL $=$ $\left.\sum\left(\mathrm{TL}_{i} N_{i}\right) / \sum N_{i}, \quad i=1, \ldots, 10\right)$. The ATL represents the central position of the population on the scale of the tide level ( $2.5 \mathrm{~m}$ intervals from the up shore to the down shore; Fig. 1b).

Growth rates were estimated using data of recaptured snails by linear regression $Y=a+b X$ on plots of FordWalford graphs (Ricker 1975), where $Y(\mathrm{~mm})$ is the shell length at recapture and $X(\mathrm{~mm})$ is the shell length at release. The purpose of this study was not the application of any existing growth models but a description of the temporal variation of the growth rate. This equation was employed due to the high empirical fit. In order to detect monthly fluctuations, growth data of the snails recaptured after a 1-month period was used for the estimate. Parameters $(a$ and $b$ ) were used to construct the growth curve of the recaptured snails. Although Takada (1995) constructed probabilistic growth curves from an arbitrary initial size, deterministic growth curves were constructed in this study according to Takada (2003). Initial sizes were selected from the peak in the size frequency histograms for the marked and released snails: $14.6 \mathrm{~mm}$ and $9.1 \mathrm{~mm}$ in April 1989, $4.2 \mathrm{~mm}$ in August 1989, $12.4 \mathrm{~mm}$ in August 1991, $4.8 \mathrm{~mm}$ in September 1991, and $3.5 \mathrm{~mm}$ in August 1992.

Size-frequency histograms of $N$. japonica were constructed for every sampling occasion by pooling the data of shell length at all the tide levels. Average shell length of a cohort was estimated by the maximum likelihood method of Aizawa and Takiguchi (1999), which enables the fitting of a set of normal curves to a size-frequency histogram by using the SOLVER routine of MS-Excel (Microsoft). This computer-aided method is a practical application of the method of Akamine (1995) that determines a set of 
parameters of normal distributions similar to other specialized programs like MIX (Macdonald and Green 1988) and NORMSEP routine of FiSAT (Gayanilo et al. 2005). The method of Aizawa and Takiguchi (1999) has recently become popular (Okuda et al. 2005; Takada 2007) because of the convenience of working on standard spreadsheet software without converting data into the other specialized programs. Although these computer-aided methods increase the objectivity in cohort separation in comparison with earlier graphical methods (Harding 1949; Cassie 1954; Bhattacharya 1967), there remain uncertainties in estimating demographic parameters from a single size frequency histogram (Grant et al. 1987). Additional information on age from growth checks on the shell or the operculum (Kideys 1996; Barroso et al. 2005) and information on growth from recaptured snails (Lewis and Bowman 1975; Creese 1981; Takada 1995, 2003) have frequently been used to reduce uncertainties. Alternatively, growth models, such as von Bertalanffy and Gompertz equations, were assumed and used as constraints on estimating a set of parameters (Kideys 1996; Quijón et al. 2001; Morton and Chan 2004). This study employed an analysis on time-series of size frequency histograms (Creese 1981; Prince et al. 1988; Castell 1997; Hermsen et al. 2003; Takada 2003, 2007; Morton and Chan 2004; Barroso et al. 2005) to minimize possible uncertainties, with additional growth information from recaptured snails. In this study, the number of normal curves fitted to a histogram was decided to minimize any abrupt changes of the number itself between the former and the next sampling occasions. Assuming the cohort showed a normal distribution with its average size close to the peak size of the histogram, identical cohorts could be defined through the series of size-frequency histograms.

Following the temporal changes of the estimated average shell length of identical cohorts, recruitment events and subsequent growth of the cohort were estimated during both sampling periods. A cohort whose average shell length was less than $10.0 \mathrm{~mm}$ was defined as a juvenile cohort because of the immaturity of the reproductive organ (Nakano and Nagoshi 1980; Sasaki 1998). The estimated growth curves of the cohorts were compared with the growth rate obtained from the recaptured snails, because it is known that the growth estimates of these two methods often show disparities (Lewis and Bowman 1975; Creese 1981; Kideys 1996). Survival rate was estimated by the Richards and Waloff's first method (Southwood and Henderson 2000), using regressions of the log-transformed number of individuals of the identical cohorts against the sampling date.

\section{Results}

Temporal fluctuations of the density

Throughout the study period, no individual of $N$. japonica was found in TL 1, the highest tide level. The study area covered the full vertical range of $N$. japonica, and the densities at the extremes of the range (TL 2 and TL 10) were very low throughout the study period (Fig. 2). The density (average of 20 quadrats at a tide level at one sampling date) reached a maximum of 66.5 (individuals $\mathrm{m}^{-2}$ ) at TL 4 in December 1989 during the 1st period, and
Fig. 2 Temporal fluctuation of the mean density $\left( \pm \mathrm{SE} / \mathrm{m}^{2}\right.$, number of quadrats $=20$ ) of Nerita japonica at nine tide levels (TL 2-TL 10). The density in TL 1 is not shown because no individual was found throughout the study period

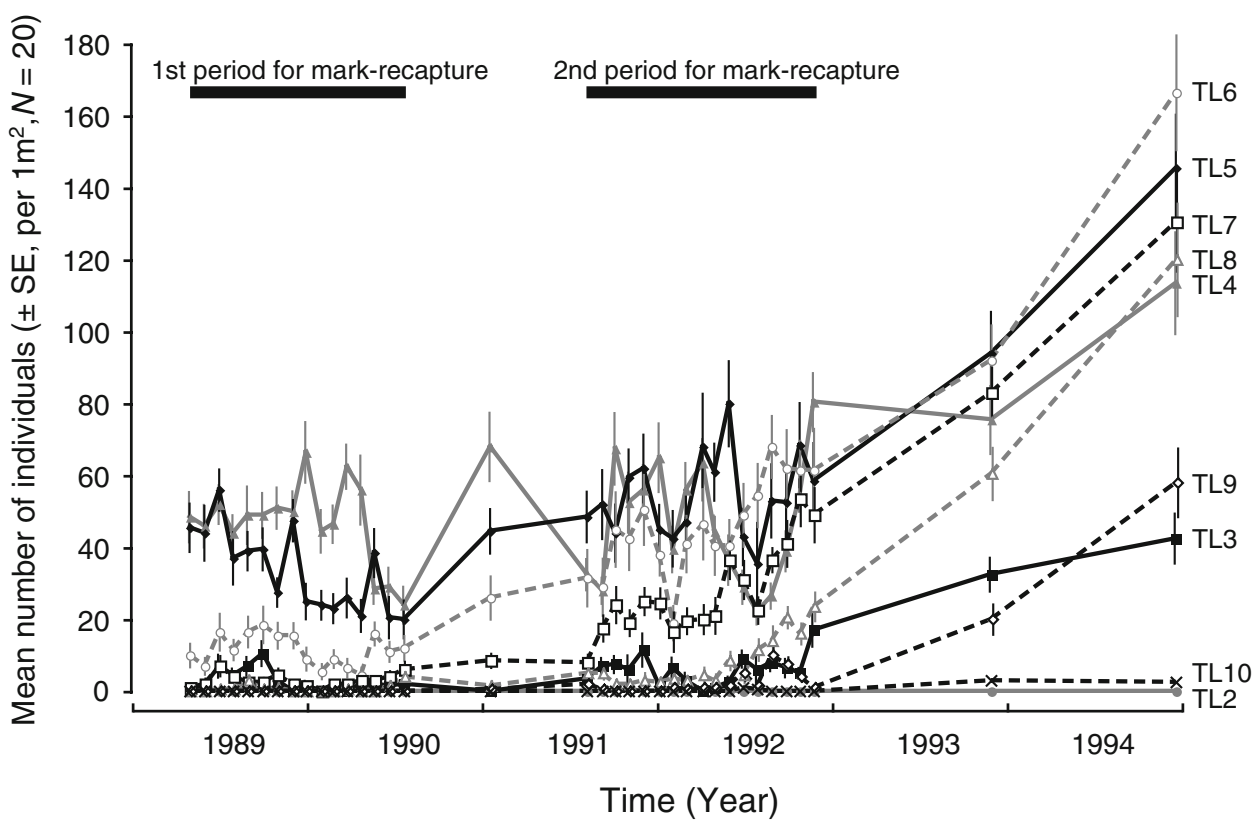


80.5 during the 2nd period at TL 4 in November 1992. Among the overall observations, the maximum density was 166.5 (individuals $\mathrm{m}^{-2}$ ) observed at TL 6 in December 1994.

The density of $N$. japonica fluctuated temporally (Fig. 2). During the 1st period (from April 1989 to July 1990) the density in TL 4 and TL 5 showed a decreasing trend, where the density was high. In the other tide levels, a long-term trend was not obvious because of the low density. On the other hand, during the 2nd period (from August 1991 to November 1992) and the additional period until December 1994, increasing trend of the density was obvious in all tide levels except TL 2 and TL 10.

\section{Vertical distribution and migration}

Pattern of the vertical distribution was stable in respect that a single peak occurred in the mid zones (TL 4-6) (Fig. 3). The vertical range of distribution was restricted in TL 2-8 in the 1st period, but the range was extended in TL 2-10 in the 2 nd period. The average tide level (ATL) of the population also varied between the 1 st and the 2 nd periods. In the 1st period, the ATL ranged between the TL 4 and TL 5 (4.42-4.88), except July 1990 (5.12). However, in the 2nd period, the ATL became lower on the shore: it ranged between TL 5 and TL 6 (5.11-5.84). Among the overall observations, the largest value (lowest on the shore) of the ATL was 6.07 in December 1994.

Most of $N$. japonica did not migrate vertically between the tide levels in all seasons (Fig. 4). Pooling all the data of the snails recaptured after 1 month $(n=857), 7.1 \%$ of the snails were recaptured at a higher tide level than they were released, and $6.8 \%$ snails were recaptured at a lower tide level than they were released. Proportions of the three migration categories (upper migrant, resident, and lower migrant snails) showed a statistically significant monthly variation (goodness-of-fit test, $d f=56, G=87.39$, $P=0.0046)$. Significant deviation from the proportion of the pooled data was observed in two cases: NovemberDecember period in 1989 and combined period of AprilJuly in 1990.

\section{Cohort separation}

During the whole study, the largest individual was $18.85 \mathrm{~mm}$ in shell length sampled at TL 7 in March 1992, and the smallest individual was $1.30 \mathrm{~mm}$ at TL 6 in August 1992. Size frequency histograms of $N$. japonica varied monthly (Fig. 5). Small individuals $(<3.00 \mathrm{~mm}$ in shell length), that represented newly recruited juveniles to the population, were observed in July, September, and December 1989 during the 1st period. In the 2nd period, small individuals were observed from August to October

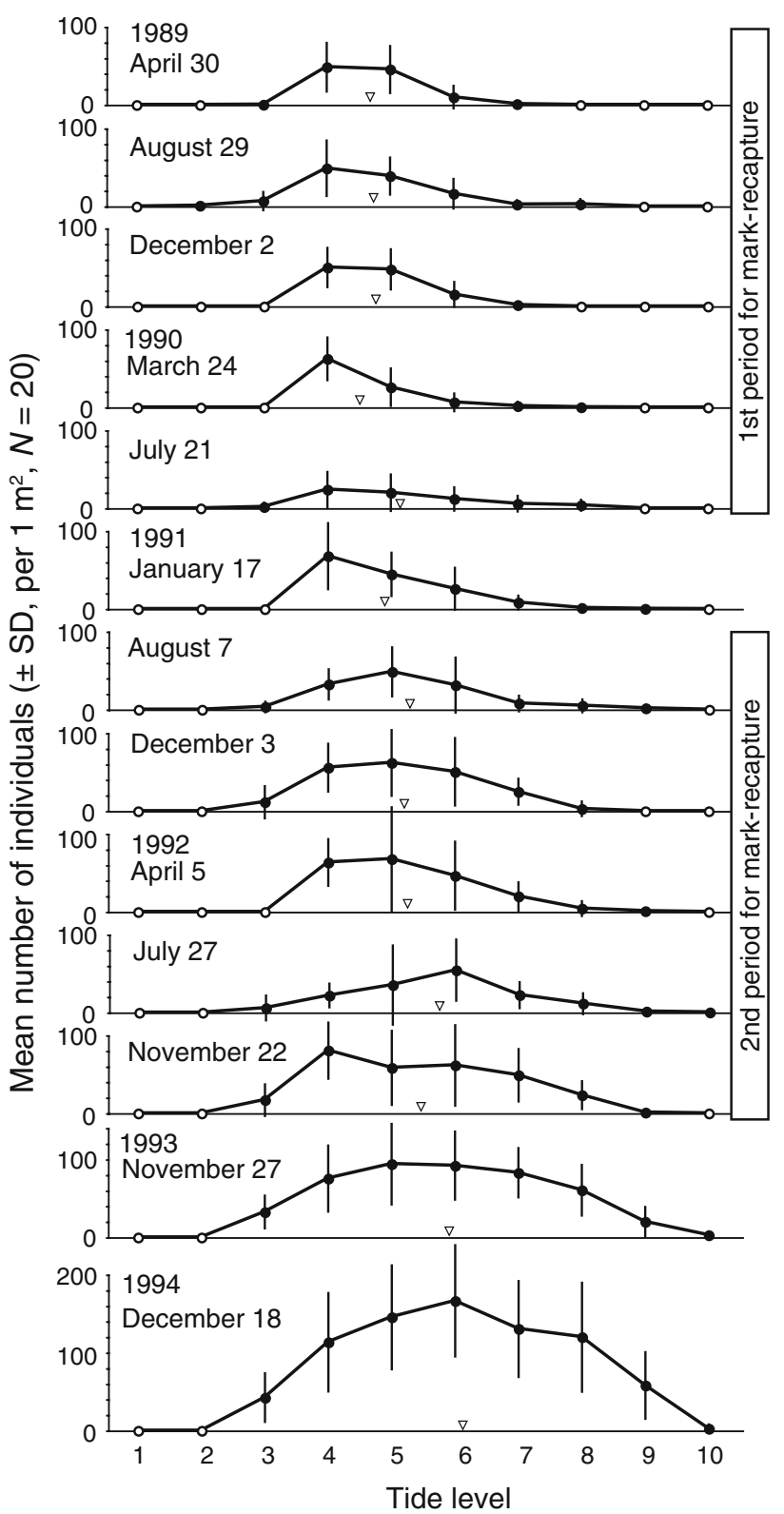

Fig. 3 Temporal changes in the vertical distribution of Nerita japonica. Mean $\pm \mathrm{SD}$ of the density $\left(/ \mathrm{m}^{2}\right.$, number of quadrats $\left.=20\right)$ are shown at each tide level. Open circles show where no individuals were sampled. Open triangles on the horizontal axes represent average tide level (ATL) of the population

1991, from December 1991 to February 1992, and from July to November 1992.

The size-frequency histogram of each sampling occasion had 1-4 peaks that were considered to represent the modal sizes of cohorts (Fig. 5). Four cohorts $(a-d)$ were detected in the 1 st period and eight cohorts $(e-l)$ were detected in the 2 nd period. Some cohorts merged into a single mode in larger shell length and could not be separated. These cohorts were labeled as a combined cohort (e.g., $b+c$ ). During the 1st and 2nd periods, cohorts with 
Fig. 4 Monthly fluctuations of the frequency of the three categories of the recaptured snails according to their vertical migration patterns. Open bars show migrants to a higher tide level, closed bars show residents which were recaptured at the same tide level where released, and shaded bars show migrants to a lower tide level. The number of recaptured snails and results of homogeneity test are listed above each column for the respective 1-month period. $n s$ not significant, $* P<0.05$

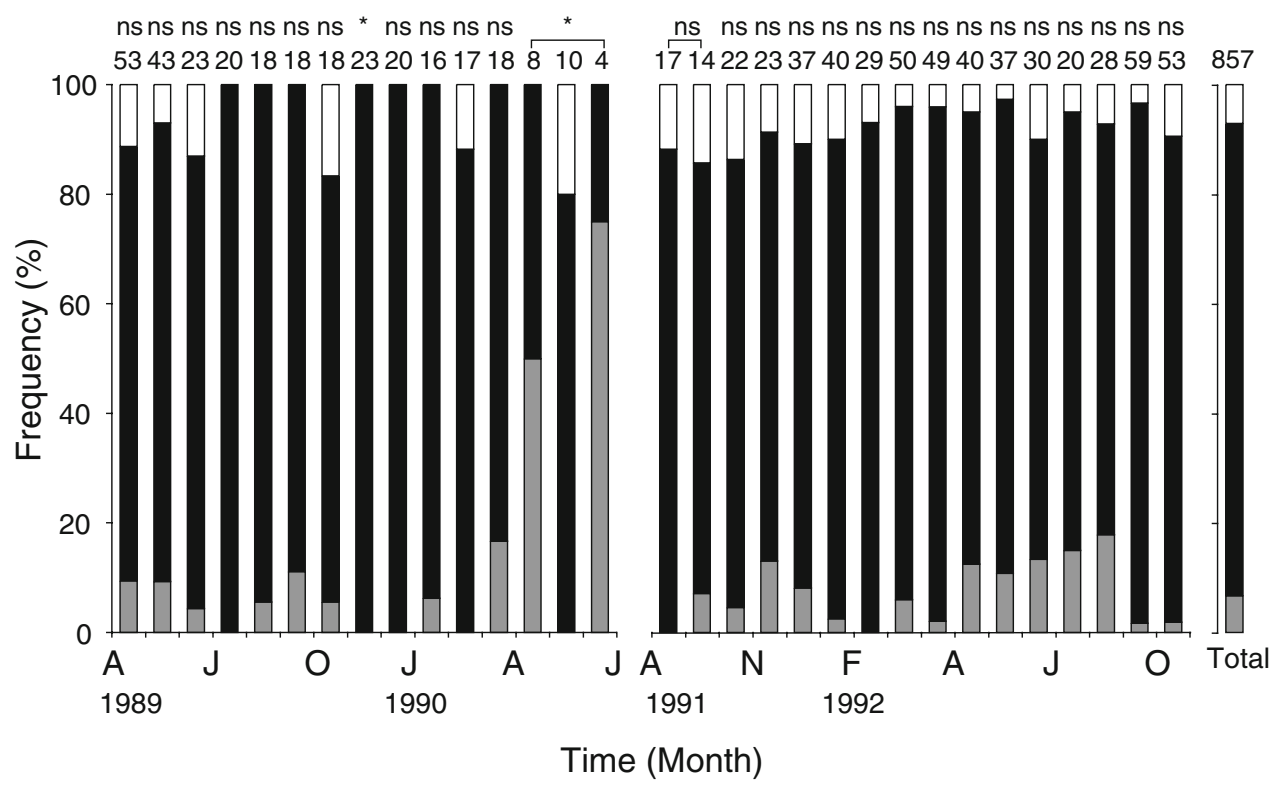

the largest average shell length were combined cohorts, except cohorts $a$ and $e$ which were present at the beginning of the sampling period. The average shell length of these combined cohorts ranged from 13.84 to $14.07 \mathrm{~mm}$ in the 1st period and 13.3 to $14.39 \mathrm{~mm}$ in the $2 \mathrm{nd}$ period.

A new cohort $(d)$ was observed in August during the 1st period, and thus one event of successful recruitment (cohort $d$ ) was recognized corresponding to the 1989 spawning season. Cohort $h$ was observed at the beginning of the 2nd period (August 1991) and could be recognized as a successfully recruited cohort. In addition to the cohort $h$, four new cohorts $(i-l)$ were observed during the 2 nd period. Two events (cohorts $h$ and $i$ ) and three events (cohorts $j, k$, and $l$ ) of successful recruitment were recognized in the 1991 and 1992 spawning seasons, respectively.

Estimated growth curves by the cohort separation showed approximately similar results with the estimated growth curves from the regression parameters of the recaptured snails (Table 1; Fig. 6). For example, average shell length of cohort $h$ was $4.8 \mathrm{~mm}$ in September 1991 and the following year it reached $11.4 \mathrm{~mm}$ in July 1992 (Fig. 6b). Estimation from the recaptured snails showed that snails of $4.8 \mathrm{~mm}$ shell length in September grew to $10.8 \mathrm{~mm}$ by the following July (Fig. 6d). Growth curves obtained by the both methods demonstrate that juvenile snails increase their shell length more than adult snails, and that both juvenile and adult snails almost stop growing during winter. Growth rates of adult and juvenile snails in the 1st period were slightly slower than those in the 2nd period (Table 2).

Estimated survival rate of $N$. japonica was also varied with size and the period (Fig. 7). In the 1st period, both adults (cohorts $a+b+c$ ) and juveniles (cohort $d$ ) decreased significantly. Estimated monthly (30-day) survival rate of the adults was $0.959(0.934-985,95 \%$ confidence interval), while 0.794 (0.711-887) for the juveniles. On the other hand, regressions for adults (cohorts $e+f+g$ ) and juveniles (cohort $h$ ) in the 2 nd period were not statistically significant $(P>0.05)$, indicating higher survivorship in this period compared to the 1 st period.

\section{Long-term changes in size-frequency histograms}

Size-frequency histograms of $N$. japonica in winter varied annually (Fig. 8). In each year, several cohorts were recognized. Two juvenile cohorts (average shell length $<10 \mathrm{~mm}$ ) were obvious in December 1994, and recognizable in the other years except in December 1989 and December 1991. Juvenile cohort comprised $9.6 \%$ of the population in December 1989, and 42.3\% in December 1994. Two adult cohorts (average shell length $\geq 10 \mathrm{~mm}$ ) were recognized in December 1989, but only one adult cohort in the later years. Except in December 1989, average shell length of adult cohorts showed the maximum at $14.7 \mathrm{~mm}$ in January 1991, with the minimum at $12.7 \mathrm{~mm}$ in December 1994. Individuals of adult cohorts were observed at TL 4-7 in December 1989 and they were observed over a wider range of tide levels in the later years.

In December 1991, most snails at TL 7 and TL 8, which were near the lowest limit of the distribution, were larger than the average shell length of the adult cohort. Also, at TL 8 in 1992 and at TL 9 in 1993, snails near the lower limit of the distribution showed larger shell length than the average of the adult cohort. The larger size adults tended to promote the gradual expansion of the distribution range to the lower shore. Juveniles also expanded their distribution range during the 6-year period. At TL 8, 12 juvenile individuals occurred in 1992 following the occurrence of 6 adults in 1991. At TL 9, 55 juvenile individuals occurred 1994 
Fig. 5 Monthly changes in the size-frequency histograms of Nerita japonica during a the 1 st period (from April 1989 to July 1990) and b the 2nd period (from August 1991 to November 1992). Samples from the ten tide levels (TL 1-10) were pooled. Arrows with lowercase letters above the histograms show the mean shell length of cohorts estimated by fitting normal curves

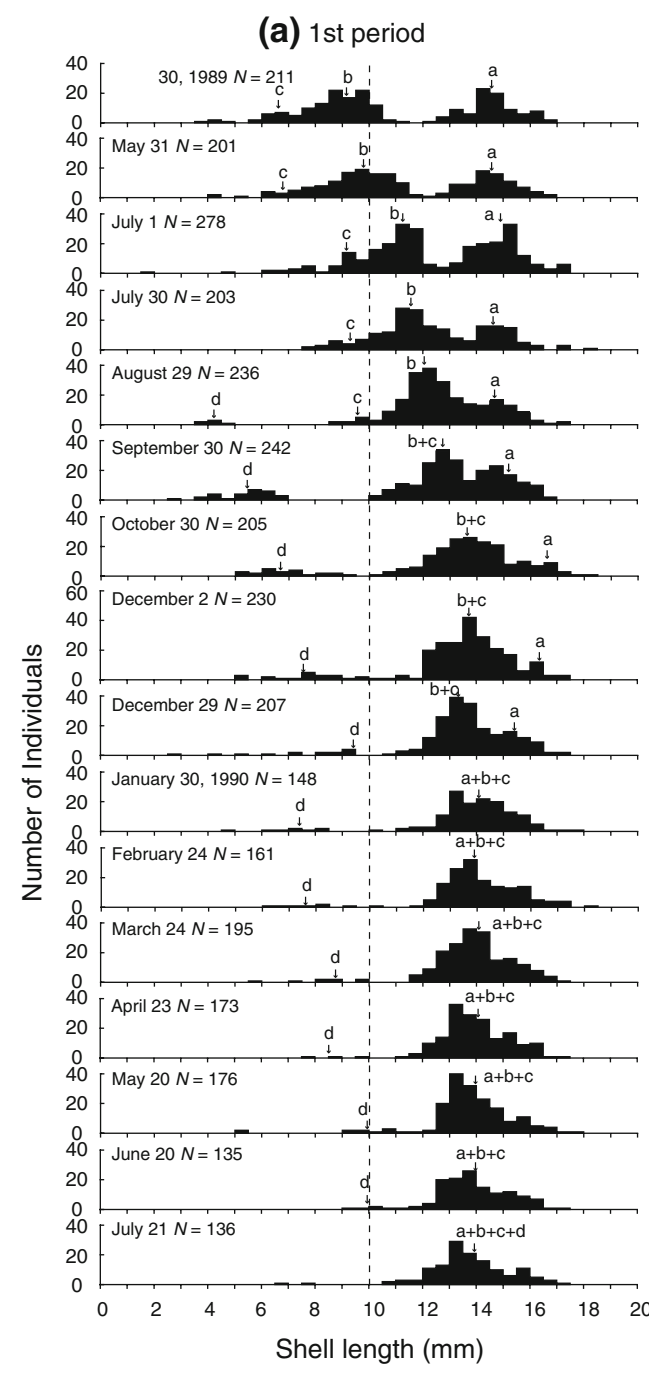

(b) 2nd period

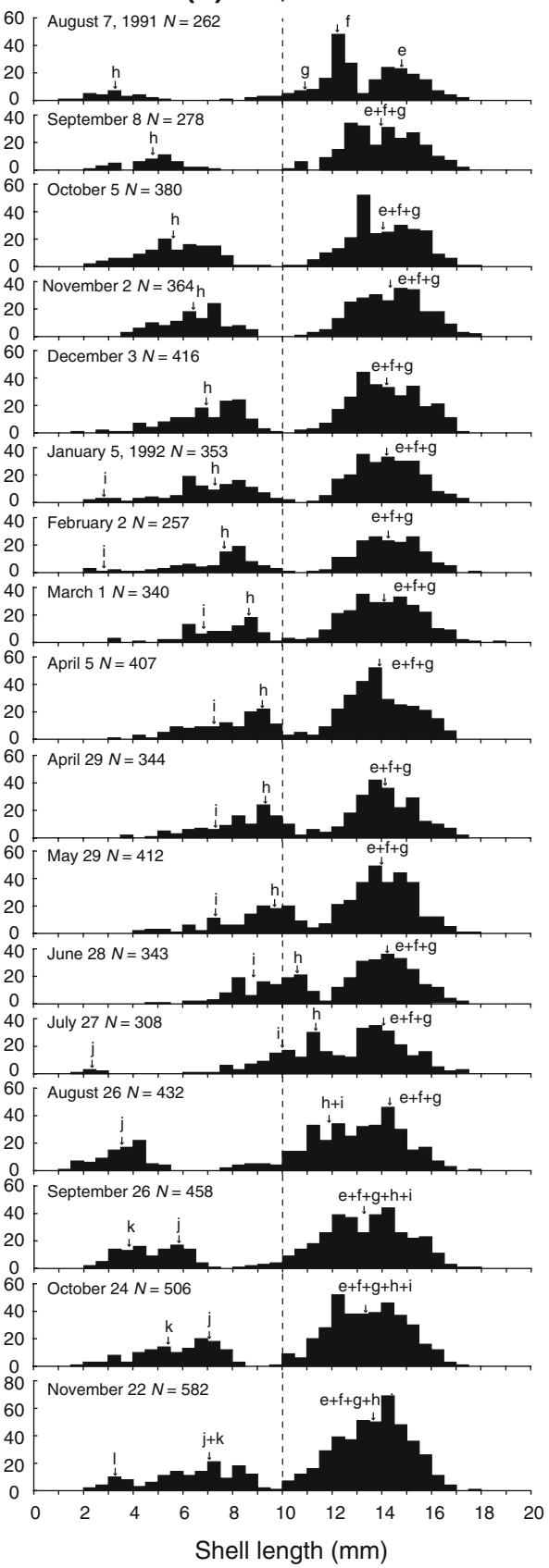

following the occurrence of 40 adults in 1993. Thus, adult snails gradually lowered the distribution range and so, with a time lag, did juvenile snails. In the upper shore direction, snails did not expand their range much. Only a few juveniles were observed at TL 3 , in contrast to the adults.

\section{Discussion}

The present study demonstrated the temporal fluctuations in population characteristics of $N$. japonica on a boulder shore. The density of the population was decreasing during the 1st period (April 1989 to July 1990) while it was increasing during the 2nd period (August 1991 to November 1992). The density increase coincided with the extension of the vertical range to the lower shore, the high proportion of juveniles in the population in winter, the increase of the number of newly recruited cohorts, and the high survival rates of adults and juveniles (Table 2). The average shell length of adults and the growth rate, however, were similar both in the 1st and 2nd periods. 
Table 1 Parameters of linear regression $(Y=a+b X)$ and coefficient of determination $\left(r^{2}\right)$, calculated from the shell length at recapture $(Y \mathrm{~mm})$ against the shell length at release $(X \mathrm{~mm})$

\begin{tabular}{|c|c|c|c|c|}
\hline Period & $n$ & $a$ & $b$ & $r^{2}$ \\
\hline \multicolumn{5}{|l|}{ 1st period } \\
\hline April 30-May 31, 1989 & 51 & 1.694 & 0.889 & 0.982 \\
\hline May 31-July 1, 1989 & 43 & 2.280 & 0.849 & 0.990 \\
\hline July 1-July 30, 1989 & 23 & 2.546 & 0.828 & 0.994 \\
\hline July 30-August 29, 1989 & 20 & 1.791 & 0.890 & 0.992 \\
\hline August 29-September 30, 1989 & 18 & 1.523 & 0.930 & 0.990 \\
\hline September 30-October 30, 1989 & 18 & 1.811 & 0.903 & 0.987 \\
\hline October 30-December 2, 1989 & 18 & 1.507 & 0.899 & 0.997 \\
\hline December 2-December 29, 1989 & 23 & 0.411 & 0.972 & 0.999 \\
\hline December 29, 1989-January 30, 1990 & 20 & 0.062 & 0.996 & 1.000 \\
\hline January 30-February 24, 1990 & 16 & 0.000 & 1.000 & 1.000 \\
\hline February 24-March 24, 1990 & 17 & 0.158 & 0.989 & 1.000 \\
\hline March 24-April 23, 1990 & 19 & 0.787 & 0.944 & 0.999 \\
\hline April 23-May 20, 1990 & 8 & 0.000 & 1.000 & 1.000 \\
\hline May 20-June 20, 1990 & 10 & 1.588 & 0.890 & 0.996 \\
\hline June 20-July 21, 1990 & 4 & 0.326 & 0.983 & 0.945 \\
\hline \multicolumn{5}{|l|}{ 2nd period } \\
\hline August 7-September 8, 1991 & 17 & 3.012 & 0.802 & 0.982 \\
\hline September 8-October 5, 1991 & 14 & 2.316 & 0.851 & 0.995 \\
\hline October 5-November 2, 1991 & 22 & 1.304 & 0.916 & 0.996 \\
\hline November 2-December 3, 1991 & 23 & 0.821 & 0.944 & 0.999 \\
\hline December 3, 1991-January 5, 1992 & 37 & 0.627 & 0.957 & 0.999 \\
\hline January 5-February 2, 1992 & 40 & 0.215 & 0.985 & 1.000 \\
\hline February 2-March 1, 1992 & 29 & 0.189 & 0.987 & 1.000 \\
\hline March 1-April 5, 1992 & 50 & 0.597 & 0.960 & 0.999 \\
\hline April 5-April 29, 1992 & 49 & 0.817 & 0.945 & 0.999 \\
\hline April 29-May 29, 1992 & 40 & 1.355 & 0.909 & 0.996 \\
\hline May 29-June 28, 1992 & 37 & 1.790 & 0.880 & 0.995 \\
\hline June 28-July 27, 1992 & 30 & 2.396 & 0.842 & 0.990 \\
\hline July 27-August 26, 1992 & 20 & 2.438 & 0.836 & 0.996 \\
\hline August 26-September 26, 1992 & 28 & 2.503 & 0.838 & 0.993 \\
\hline September 26-October 24, 1992 & 59 & 1.802 & 0.879 & 0.997 \\
\hline October 24-November 22, 1992 & 53 & 1.498 & 0.901 & 0.998 \\
\hline
\end{tabular}

The growth rate of $N$. japonica varied seasonally and annually (Fig. 6). However, the estimated growth curves showed a general lifetime pattern of shell growth. Newly recruited juveniles with ca. $5 \mathrm{~mm}$ shell length in the fall reach to ca. $7 \mathrm{~mm}$ by the winter then apparently stop growing. They increase their shell length from spring to fall and reach to ca. $13 \mathrm{~mm}$ in the next winter then stop growing again. The next warm season, they reach to ca. $14 \mathrm{~mm}$ in shell length. The seasonal growth pattern in the present study is similar to that shown in previous studies (Suzuki 1935; Nakano and Nagoshi 1980, 1983). However, results of the present study demonstrated that $N$. japonica in Amakusa showed slightly better growth $\left(2.4 \times 10^{-2} \mathrm{~mm}\right.$ day $^{-1}$ in juvenile shell length in summer) than that $\left(2.1 \times 10^{-2} \mathrm{~mm} \mathrm{day}^{-1}\right)$ in Shima Peninsula $\left(34^{\circ} \mathrm{N}, 137^{\circ} \mathrm{E}\right)$ observed in previous studies (Nakano and Nagoshi 1980, 1983).

Population processes in decreasing and increasing phases

Abe (1980) suggested two possible extinction processes in local populations of $N$. japonica at Tanabe Bay, Japan: one was the lack of recruitment of juveniles and the other was accidental mass mortality of adults. A recruitment failure was also observed in the present study. The number of newly recruited juveniles was very low after the reproductive season in 1989 (Fig. 5) and most of them died out before the next summer (Fig. 7). On the other hand, no event of mass mortality of adults was recognized in the present study. The survival rate of adults in the 1st period was lower than that in the 2nd period (Fig. 7). During the decrease in abundance, the vertical range of the distribution did not change but the density decreased (Figs. 2, 3). At Tanabe Bay, the lack of recruitment in several consecutive years resulted in the local extinction, because the estimated longevity of $N$. japonica in Tanabe Bay was 3-4 years (Abe 1980). In the present study at Amakusa, some juveniles successfully recruited to the population after the reproductive season in 1990, the year following the recruitment failure.

Frequent failure of recruitment has been observed in several gastropod species in temperate intertidal zones (Kendall et al. 1987). The relatively long longevity of benthic adults, however, tends to buffer any annual fluctuations in recruitment success. Therefore, if the causes of recruitment failure continue for a longer period than the longevity, the probability of local extinction would increase. Failure of recruitment is also a proximate cause of the local extinction of an Umbonium moniliferum (Lamarck) (Gastropoda: Trochidae) population on a sandflat (Tamaki 1994). Although the present study did not focus on factors for the recruitment failure, Abe (1980) suggested a case of developmental disorder of larval $N$. japonica in the egg capsules due to seawater pollution.

The contrasting population characteristics between the increasing and the decreasing phases suggested some of the processes worked in reverse during the two phases (Table 2). In the increasing phase, successful recruitment of juveniles was observed 2-3 times a year (Fig. 5), coupled with high survival (Fig. 7). This suggests that the production and the development of juveniles were temporally synchronized in the population, but there was no direct evidence that individual females produce egg capsules several times a year. The growth rate was slightly higher during the increasing phase, but the average shell length of adult cohorts was similar in both phases. 
Fig. 6 Growth curves of Nerita japonica estimated by the cohort separation during a the 1 st period and $\mathbf{b}$ the 2 nd period. Estimated average $( \pm \mathrm{SD})$ of the normal curves fitted to the sizefrequency histograms (Fig. 5) are shown. Lowercase letter beside each growth curve corresponds to the same cohorts in Fig. 5. Comparable growth curves estimated from the regression parameters of the recaptured individuals (Table 1) are also shown for $\mathbf{c}$ the 1 st period and $\mathbf{d}$ the 2 nd period. Open circles represent initial shell length for the respective estimated growth curves
Table 2 Summary of population characteristics of Nerita japonica during the $1 \mathrm{st}$ (decreasing) and 2nd (increasing) periods of markrecapture a The minimum value - the maximum value during the each period (a) 1st period, cohorts
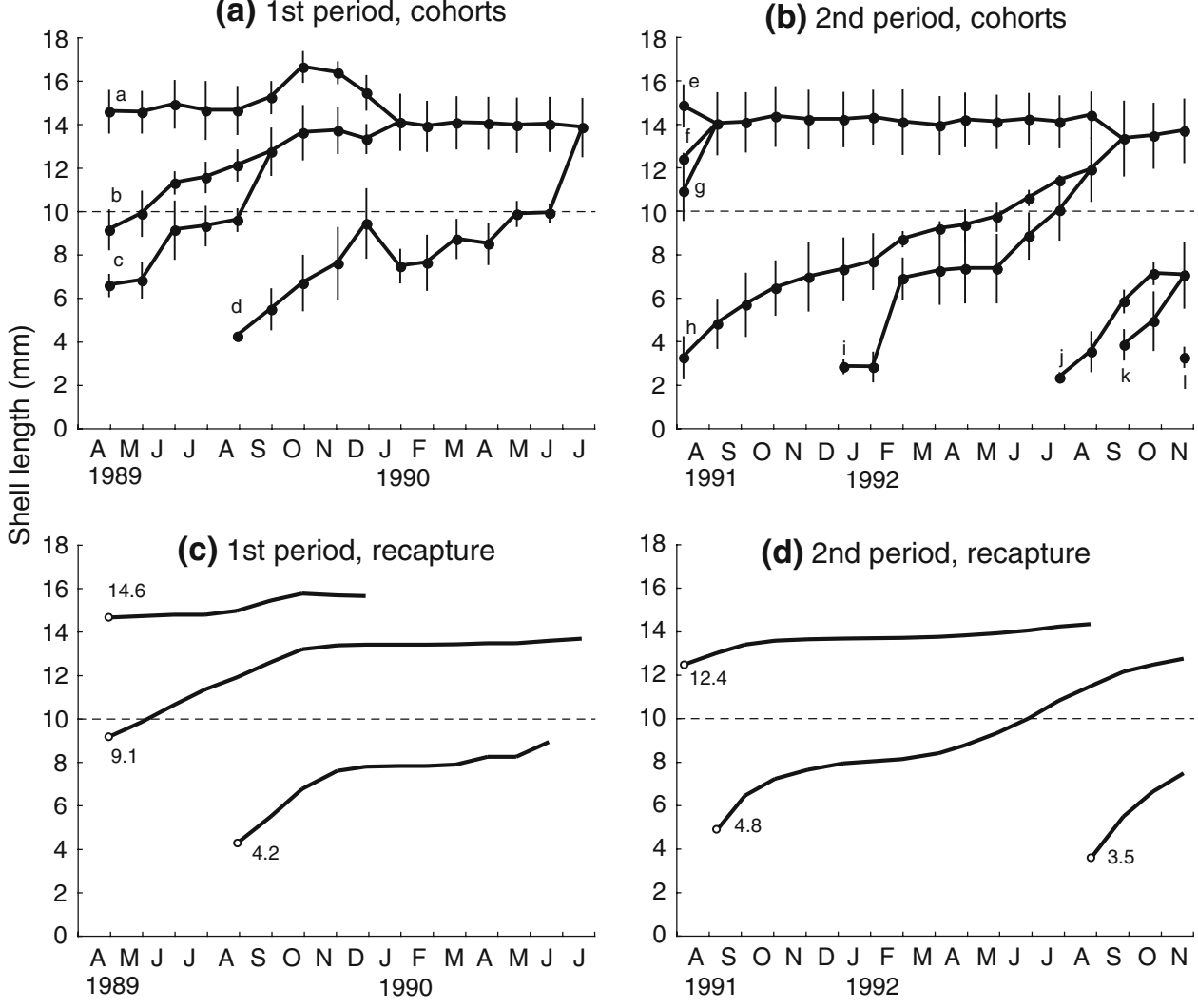

18 (d) 2nd period, recapture

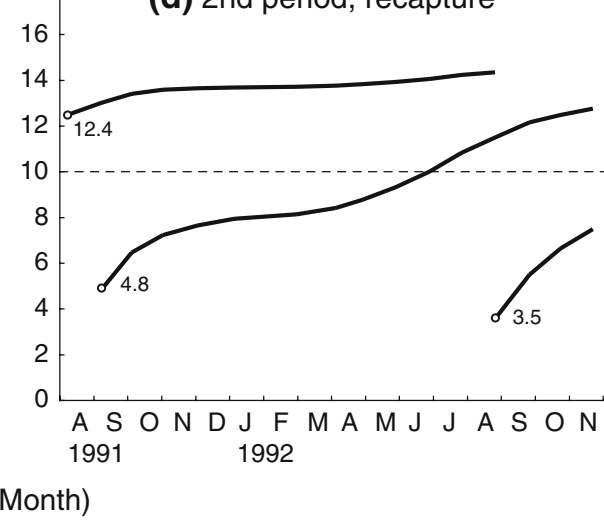

\begin{tabular}{lll}
\hline & 1 st period & 2nd period \\
\hline Average tide level (TL) & $4.42-5.12^{\mathrm{a}}$ & $5.11-5.84^{\mathrm{a}}$ \\
Vertical range in winter (TL) & & \\
Adults & $4-7^{\mathrm{a}}$ & $3-8^{\mathrm{a}}$ \\
Juveniles & $4-6^{\mathrm{a}}$ & $4-7^{*}$ \\
Monthly peak density (m ${ }^{-2}$ ) & $24.0-66.5^{\mathrm{a}}$ & $42.5-80.5^{\mathrm{a}}$ \\
$\quad$ along the tide levels & 9.6 & 32.7 \\
Percent of juveniles in winter & $13.84-14.07^{\mathrm{a}}$ & $13.31-14.39^{\mathrm{a}}$ \\
Average shell length of adults (mm) & & \\
Growth rate (mm day ${ }^{-1}$ ) & $2.68 \times 10^{-3}$ & $4.75 \times 10^{-3}$ \\
Adults (May-August) & $5.24 \times 10^{-4}$ & $1.25 \times 10^{-3}$ \\
$\quad$ November-February) & $2.30 \times 10^{-2}$ & $2.44 \times 10^{-2}$ \\
Juveniles (May-August) & $2.73 \times 10^{-3}$ & $8.87 \times 10^{-3}$ \\
$\quad$ November-February) & 1 in 1989 & 2 in 1991 and 3 in 1992 \\
Number of newly recruited cohorts & & \\
Survival rate (per 30 days) & 0.959 & Not significantly different from 1 \\
Adults & 0.794 & Not significantly different from 1 \\
Juveniles & & \\
\hline
\end{tabular}

The present results of the growth curve showed that the juveniles recruited at the beginning of the recruitment season (August-February) can grow to the adult size (10 $\mathrm{mm}$ in shell length) by the reproductive season of the following year. But juveniles that recruited late in the season may not reproduce in the following year. Under high survival of juveniles, as in the 2nd period, early recruitment within the season and early maturation to reproduction form a positive feedback for population increase. 


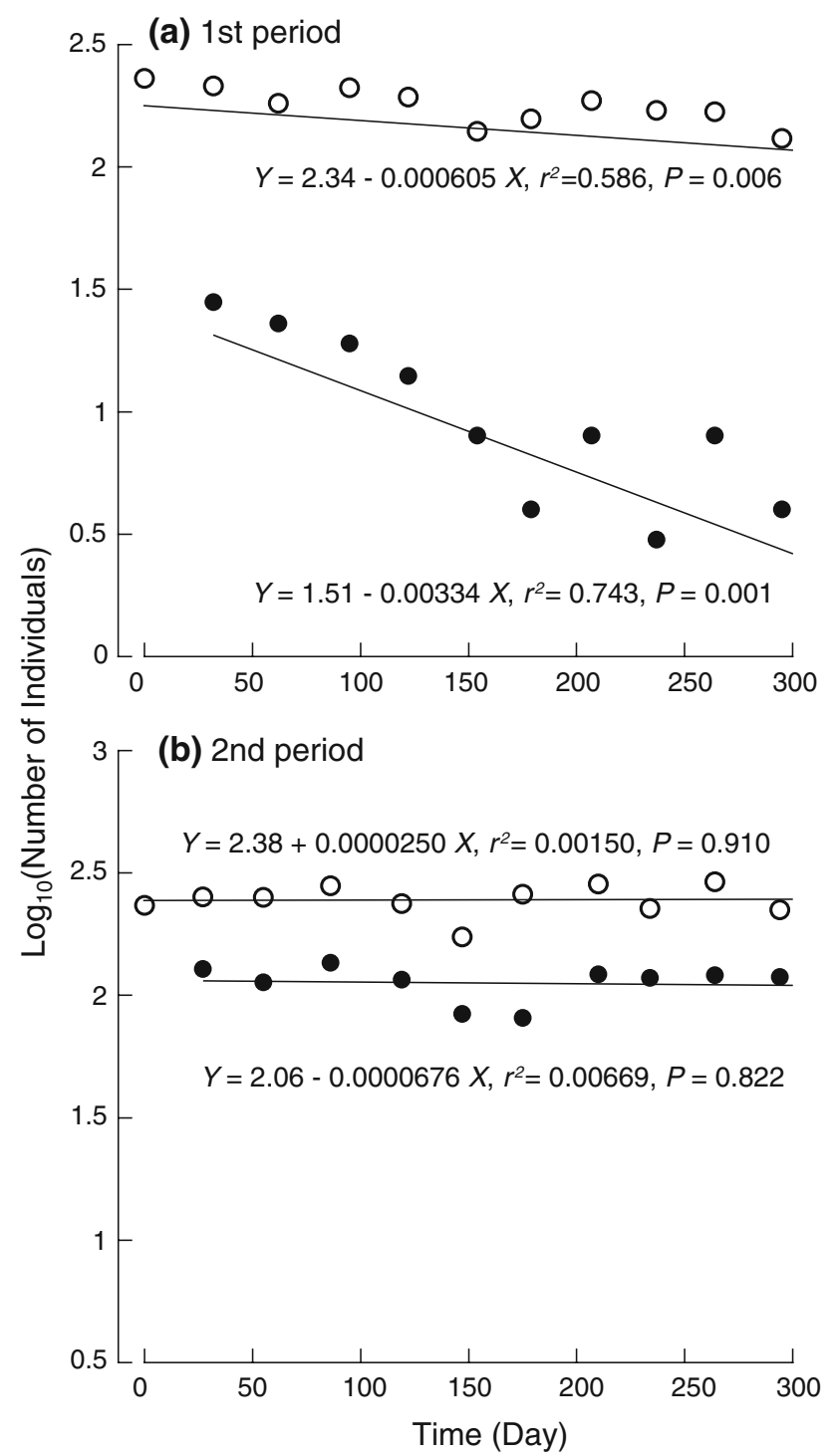

Fig. 7 Estimation of survival of cohorts by regression $Y=a+b X$, where $Y$ is the $\log _{10}$-transformed number of individuals in cohorts and $X$ is the number of days from a August 29, 1989 in the 1st period and b September 8, 1991 in the 2 nd period. Regression parameter $b$ equals to $\log _{10}(S)$, where $S$ is the daily survival rate $\left(N_{t+1}=S N_{t}, N_{t}\right.$ is the number of individuals at day $t$ ). Open circles represent adult cohorts: a cohort $a+b+c$ and $\mathbf{b}$ cohort $e+f+g$. Closed circles represent juvenile cohorts: a cohort $d$ and $\mathbf{b}$ cohort $h$

In the 2nd period, the extension of the vertical range also contributed to the population increase. The present results of the mark-recaptured snails, however, showed a low frequency of up or down migration on the shore after a 1month period (Fig. 4) in comparison to Monodonta labio (Linnaeus) and Littorina brevicula (Philippi) that occurred on the same boulder shore (Takada 1996, 2003). The present results of mark-recaptured snails did not detect any significant increase of vertical migration in the 2nd period, when the range of vertical distribution extended (Fig. 2). This discrepancy is considered as an artifact of the difference in time scale. The mark-recapture procedure focused on monthly process, while the range extension was a yearly process.

The vertical range and movement patterns of intertidal gastropods have been shown to vary with density (Mackay and Underwood 1977; Byers 2000). In the present study, the extension of the vertical range followed the increase of density. However, the present study did not investigate evidence whether density increase would promote any behaviors of downward migration. Increased density may increase the number of individuals migrating downwards on the shore even though the proportion of downward dispersal is unchanged. It is worth noting that juveniles tended to expand their distribution to the new lower tide levels in the following year of the adult occurrence. A possible explanation is that the dispersed adult produced juveniles at the lower tide levels.

The processes of population fluctuation were summarized as follows. In the decreasing phase: (1) recruitment of juveniles failed and (2) low rate of survival resulted in the density decrease with unchanged range of the vertical distribution. In the increasing phase: (1) several events of recruitment occurred in a year, (2) survival rate was high, and (3) the vertical distribution range extended to the lower zone with the density increase.

\section{Direct-developing species as a potential indicator}

In general, species without planktonic dispersal stages are at risk of local extinction by habitat deterioration occurring at local scales $(<1 \mathrm{~km})$ and may be less persistent over geological time, whereas species with dispersal stages are able to overcome local habitat deterioration by recruitment from other areas (Jablonski 1986; Pechenik 1999). In the short term, dispersal ability of the species affects the structure of spatially scattered local populations.

Comparisons of population processes of co-occurring congeneric species with different dispersal modes are worthwhile in order to estimate risk of local extinction by environmental deterioration. Nerita japonica has a congeneric co-occurring planktonic disperser $N$. albicilla Linnaeus. Takenouchi and Yamato (2002) tried to compare the local extinction and recovery processes of these Nerita spp. and inferred that both $N$. japonica and $N$. albicilla populations had been reduced in Tanabe Bay by the 1990s, but recently only $N$. albicilla that has a planktonic larval stage has increased toward recovery. On the other hand, comparisons of two species of gastropods, Batillaria spp., on tidal flats in Japan revealed that Batillaria multiformis (Lischke), a planktonic disperser, has a higher risk of extinction than co-occurring Batillaria cumingi (Crosse) that produces benthic juveniles without a planktonic dispersal stage (Furota et al. 2002). Although these two cases 
Fig. 8 Six-year annual changes in the size-frequency histograms of Nerita japonica. Samples from all tide levels were cumulated. TL 1 and TL 2 are omitted because no individuals were observed at TL 1 and TL 2 on the sampling occasions. Arrows above the histograms show the mean shell length of cohorts estimated by fitting normal curves. Pie charts represent proportion of tide levels for individuals included in juvenile cohorts (left) and adult cohorts (right).

Proportions of individuals included in juvenile cohorts are shown. $N$ Number of total individuals

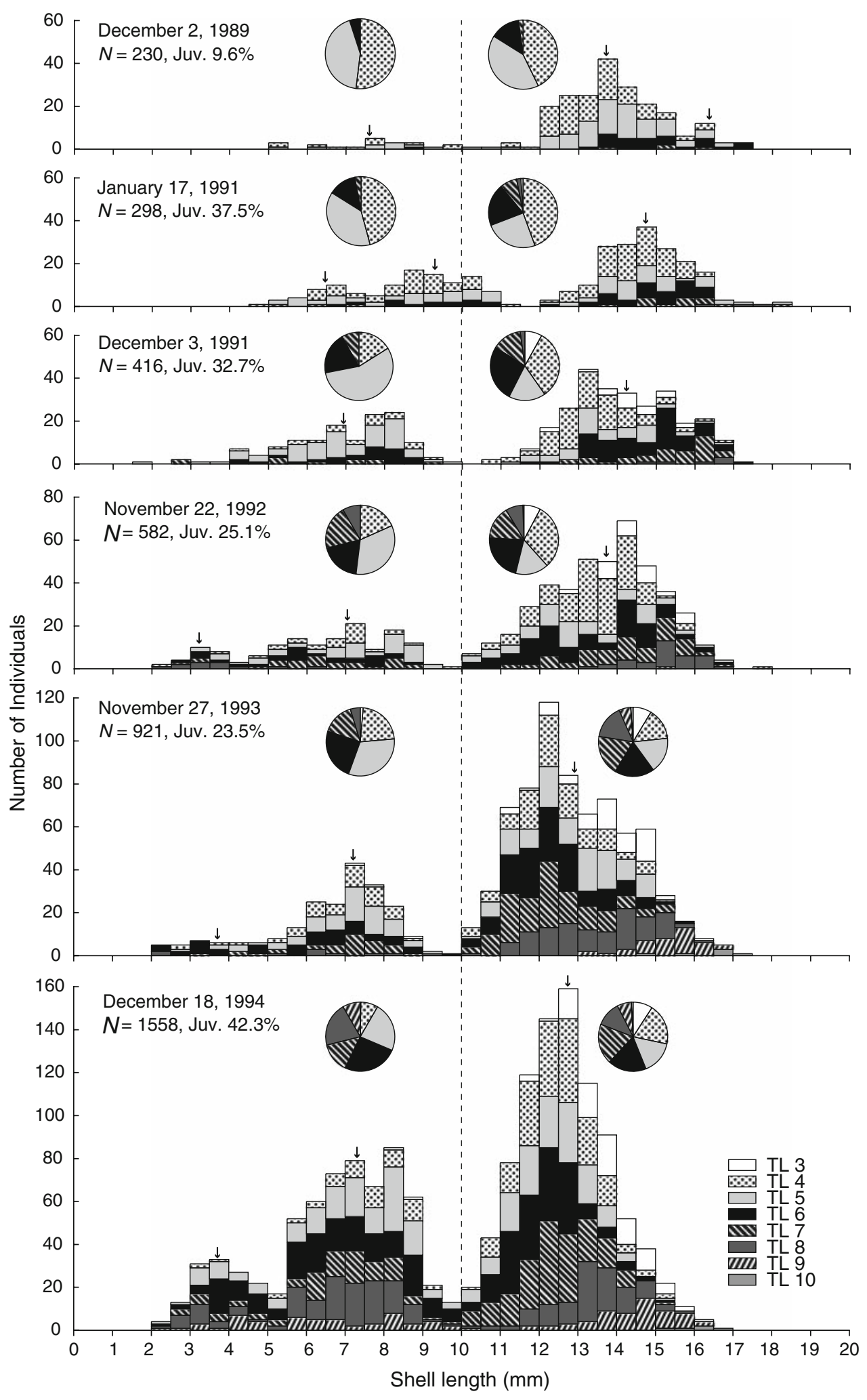

for the direct developer $N$. japonica and the planktonic disperser $B$. multiformis appear to be contradictory, recruitment failure is considered to be a primary factor for the extinction risk in both cases. Different spatial mechanisms would affect recruitment failure for direct developers and planktonic dispersers. 
Oceanic currents affect dispersal of planktonic larvae and subsequent success in recruitment to appropriate benthic habitats (Gaylord and Gaines 2000). Planktonic eggs and larvae are vulnerable to planktonic and benthic predators, false chemical cues during metamorphosis and settlement, and dispersal away from favorable habitats, while benthic egg masses are vulnerable to benthic predators and environmental stresses including pollutants (Pechenik 1999). These mechanisms for planktonic dispersers work in larger spatial scales than those for direct developers. Therefore, a difference in dispersal scales shows a potential for indicator of environmental stresses in different spatial scales (Jones and Kaly 1996). In the case of Nerita spp. in Tanabe Bay, supposed environmental stressors deteriorated on both local and regional scales (although not explicitly defined in Takenouchi and Yamato 2002) and later recovered in the regional scale. Simultaneous monitoring of both a direct developer and a planktonic disperser will give detailed information on the scales of environmental deterioration.

Furota et al. (2002) discussed that the planktonic $B$. multiformis is vulnerable to environmental deterioration at regional scales $(10-100 \mathrm{~km})$, such as overall decrease in the favorable benthic habitats and frequent occurrence of hypoxic seawater that negatively affects planktonic larvae. On the other hand, the life history of $N$. japonica is affected by factors operating at local scales $(<1 \mathrm{~km})$, such as accumulation of polluted sediment on the shore habitats. The results of Abe (1980) and the present study indicate that recruitment of $N$. japonica is a better candidate for monitoring the local (habitat) environment than the other population characteristics. Recruitment failure can be effectively monitored by size frequency histograms in winter. The density and the vertical range on the shore can be observed by ordinary quantitative samplings in any season. Monitoring the average shell length of adults and the growth rate, however, is not effective because they showed similar values both in the increasing and decreasing phases.

In conclusion, a population of $N$. japonica on a boulder shore showed contrasting characteristics between increasing and decreasing phases. Population characteristics, especially success of recruitment, are potentially useful criteria for monitoring changes of shore environment on a local scale.

Acknowledgments I am grateful to Prof. T. Kikuchi for giving me the opportunity to study this subject and supervising this work. I also thank Prof. M. Tanaka, K. Mori, K. Nandakumar and S. Nishihama for valuable suggestions during the course of this study. Comments made by S. Nishihama improved the manuscript. This study was partly supported by the Grant-in-aid for Scientific Research, from the Ministry of Education, Science, Sports and Culture, Japan (63480007) and the JSPS Fellowship for Junior Scientists (1182).

\section{References}

Abe N (1980) Extinction of the populations of Heminerita japonica (Dunker) in the inner part of Tanabe Bay (in Japanese). Nankiseibutu 22:21-25

Aizawa Y, Takiguchi N (1999) Consideration of the methods for estimating the age-composition from the length frequency data with MS-Excel (in Japanese). Bull Jpn Soc Fish Oceanogr 63:205-214

Akamine T (1995) A mathematical study of fish growth formula in population dynamics (in Japanese with English abstract). Bull Natl Res Inst Fish Sci 7:189-263

Barroso CM, Moreira MH, Richardson CA (2005) Age and growth of Nassarius reticulatus in the Ria de Aveiro, north-west Portugal. J Mar Biol Assoc UK 85:151-156

Bhattacharya C (1967) A simple method of resolution of a distribution into Gaussian components. Biometrics 23:115-135

Byers JE (2000) Effects of body size and resource availability on dispersal in a native and a non-native estuarine snail. J Exp Mar Biol Ecol 248:133-150

Cappuccino N (1995) Novel approaches to the study of population dynamics. In: Cappuccino N, Price PW (eds) Population dynamics: new approaches and synthesis. Academic Press, San Diego, pp 3-16

Cassie RM (1954) Some uses of probability paper in the analysis of size frequency distributions. Aust J Mar Freshw Res 5:513-522

Castell LL (1997) Population studies of juvenile Trochus nilotics on a reef flat on the north-eastern Queensland coast, Australia. Mar Freshw Res 48:211-217

Creese RG (1981) Patterns of growth, longevity and recruitment of intertidal limpets in New South Wales. J Exp Mar Biol Ecol $51: 145-171$

Furota T, Sunobe T, Arita S (2002) Contrasting population status between the planktonic and direct-developing batillariid snails Batillaria multiformis (Lischke) and B. cumingi (Crosse) on an isolated tidal flat in Tokyo Bay. Venus 61:15-23

Gayanilo FC Jr, Sparre P, Pauly D (2005) FAO-ICLARM stock assessment tools II (FiSAT II), revised version user's guide. FAO computerized information series (Fisheries) 8

Gaylord B, Gaines SD (2000) Temperature or transport? Range limits in marine species mediated solely by flow. Am Nat 155:769-789

Grant A, Morgan PJ, Olive PJW (1987) Use made in marine ecology of methods for estimating demographic parameters from size/ frequency data. Mar Biol 95:201-208

Grantham BA, Eckert GL, Shanks AL (2003) Dispersal potential of marine invertebrates in diverse habitats. Ecol Appl 13:S108S116

Grimm V, Reise K, Strasser M (2003) Marine metapopulations: a useful concept? Helgoland Mar Res 56:222-228

Habe T (1960) Egg masses and egg capsules of some Japanese marine prosobranchiate gastropod. Bull Mar Biol Stn Asamushi 10:121126

Harding JP (1949) The use of probability paper for the graphical analysis of polymodal frequency distributions. J Mar Biol Assoc UK 28:141-153

Hermsen JM, Collie JS, Valentine PC (2003) Mobile fishing gear reduces benthic megafaunal production on George Bank. Mar Ecol-Prog Ser 260:97-108

Jablonski D (1986) Larval ecology and macroevolution in marine invertebrates. Bull Mar Sci 39:565-587

Jones GP, Kaly UL (1996) Criteria for selecting marine organisms in biomonitoring studies. In: Schmitt RJ, Osenberg CW (eds) Detecting ecological impacts: concepts and applications in coastal habitats. Academic Press, San Diego, pp 29-48 
Kendall MA, Williamson P, Garwood PR (1987) Annual variation in recruitment and population structure of Monodonta lineata and Gibbula umbilicalis populations at Aberaeron, Mid-Wales. Estuar Coast Shelf Sci 24:499-511

Kideys AE (1996) Determination of age and growth of Buccinum undatum L. (Gastropoda) off Douglas, Isle of Man. Helgoländer Meeresunters 50:353-368

Koike K (1996) Embryonic development and larval dispersal in the Neritidae (Gastropoda: Prosobranchia). Galaxea 13:129-130; (abstract)

Lewis JR, Bowman RS (1975) Local habitat-induced variations in the population dynamics of Patella vulgata L. J Exp Mar Biol Ecol 17:165-203

Mackay DA, Underwood AJ (1977) Experimental studies on homing in the intertidal patellid limpet Cellana tramoserica (Sowerby). Oecologia 30:215-237

Macdonald PDM, Green PEJ (1988) User's guide to program MIX: an interactive program for fitting mixtures of distributions. Ichthus data systems, Ontario

Morton B, Chan K (2004) The population dynamics of Nassarius festivus (Gastropoda: Nassariidae) on three environmentally different beaches in Hong Kong. J Mollus Stud 70:329-339

Nakano D, Nagoshi M (1980) Growth and age structure of Heminerita japonica (Dunker), population of the Shima Peninsula, Japan (Prosobranchia) (in Japanese with English abstract). Venus 39:101-108

Nakano D, Nagoshi M (1983) Seasonal changes of the age composition and growth rate in an intertidal population of Heminerita japonica Dunker (Prosobranchia; Neritidae) (in Japanese with English abstract). Venus 42:259-268

Ohgaki S (1989) Long-term change in the coastal biota of Hatakejima Island. Jpn J Ecol 39:27-36 (in Japanese with English abstract)

Okuda N, Hamaoka H, Omori K (2005) Life history and ecology of the glowbelly Acropoma japonicum in the Uwa Sea, Japan. Fish Sci 71:1042-1048

Paruntu CP, Tokeshi M (2003) Variability in the reproductive characteristics of local populations of an intertidal gastropod, Nerita japonica (Dunker). Benthos Res 58:7-14

Pechenik JA (1999) On the advantages and disadvantages of larval stages in benthic marine invertebrate life cycles. Mar Ecol-Prog Ser 177:269-297

Prince JD, Sellers TL, Ford WB, Talbot SR (1988) Recruitment, growth, mortality and population structure in a southern
Australian population of Haliotis rubra (Mollusca: Gastropoda). Mar Biol 100:75-82

Quijón P, Contreras H, Jaramillo E (2001) Population biology of the intertidal snail Chilina ovalis Sowerby (Pulmonata) in the Queule River estuary, south-central Chile. Estuaries 24:69-77

Ricker WE (1975) Computation and interpretation of biological statistics of fish populations. Bull Fish Res Bd Can 191:1-382

Sasaki T (1998) Comparative anatomy and phylogeny of the recent Archaeogastropoda (Mollusca: Gastropoda). Univ Mus Univ Tokyo Bull 38:1-223

Southwood TRE, Henderson PA (2000) Ecological methods, 3rd edn. Blackwell, Malden

Suzuki S (1935) On the age and growth of Nerita japonica Dunker. Sci Rep Tohoku Imp Univ Biol 10:247-256

Takada Y (1995) Variation of growth rate with tidal level in the gastropod Monodonta labio on a boulder shore. Mar Ecol-Prog Ser 117:103-110

Takada Y (1996) Vertical migration during the life history of the intertidal gastropod Monodonta labio on a boulder shore. Mar Ecol-Prog Ser 130:117-123

Takada Y (2001) Comparison of the activity patterns of nine molluscan grazers on a boulder shore at Amakusa, Japan. Venus 60:157-172

Takada Y (2003) Dimorphic migration, growth, and fecundity in a seasonally split population of Littorina brevicula (Mollusca: Gastropoda) on a boulder shore. Popul Ecol 45:141-148

Takada Y (2007) Seasonal and long-term fluctuations in a population of Patelloida heroldi (Mollusca: Gastropoda) on a boulder shore in Japan. Venus 66:85-97

Takada Y, Kikuchi T (1990) Mobile molluscan communities in boulder shores and the comparison with other intertidal haitats in Amakusa. Publ Amakusa Mar Biol Lab 10:145-168

Takada Y, Kikuchi T (1991) Seasonal and vertical variation of the boulder shore fauna in Amakusa. Publ Amakusa Mar Biol Lab 11:1-17

Takenouchi K, Yamato S (2002) Distribution of neritid gastropods in Tanabe Bay and a transportation experiment of Nerita japonica to Hatakejima (in Japanese with English abstract). Nankiseibutu 44:98-102

Tamaki A (1994) Extinction of the trochid gastropod, Umbonium (Suchium) moniliferum (Lamarck), and associated species on an intertidal sandflat. Res Popul Ecol 36:225-236 